\title{
Impact of Adjuvant Radiotherapy and Reversibility of Neurogenic Bladder on Bladder Storage Function and Impact of Urethral Resistance on Bladder Emptying Function after Radical Hysterectomy
}

\author{
Noritoshi Sekido,2, Takayuki Yoshino1, Eiichiro Takaoka1, Natsui Waku1, Ken Tanaka1, \\ Hiroyuki Nishiyama3, Hiroyuki Ochi', Toyomi Satoh ${ }^{4}$ \\ ${ }^{1}$ Department of Urology, Tsukuba University Hospital, Ibaraki, Japan \\ ${ }^{2}$ Department of Urology, School of Medicine, Faculty of Medicine, Toho University Ohashi Medical Center, Tokyo, Japan \\ ${ }^{3}$ Urology and Andrology, Majors of Medical Sciences, Graduate School of Comprehensive Human Sciences, University of \\ Tsukuba, Ibaraki, Japan \\ ${ }^{4}$ Departments of Obstetrics and Gynecology, Faculty of Medicine, University of Tsukuba, Ibaraki, Japan \\ Email: nsekido@med.toho-u.ac.jp
}

How to cite this paper: Sekido, N., Yoshino, T., Takaoka, E., Waku, N., Tanaka, K., Nishiyama, H., Ochi, H. and Satoh, T. (2017) Impact of Adjuvant Radiotherapy and Reversibility of Neurogenic Bladder on Bladder Storage Function and Impact of Urethral Resistance on Bladder Emptying Function after Radical Hysterectomy. Open Journal of Urology, 7, 252-265. https://doi.org/10.4236/oju.2017.712030

Received: November 6, 2017

Accepted: December 25, 2017

Published: December 28, 2017

Copyright $\odot 2017$ by authors and Scientific Research Publishing Inc. This work is licensed under the Creative Commons Attribution International License (CC BY 4.0).

http://creativecommons.org/licenses/by/4.0/

c) (7) Open Access

\begin{abstract}
Purpose: To clarify which patients need careful neurourological management after abdominal radical hysterectomy (RH) by investigating the effects of adjuvant radiotherapy and reversibility of neurogenic bladder (NB) on the storage function as well as the effects of urethral resistance on the emptying function. Methods: Data from sixty-two patients referred to our NB clinic after RH were retrospectively reviewed. Findings of urodynamic studies performed at 3 (UDS-1) and 12 (UDS-2) months after treatment were compared, and logistic analysis was used to calculate the odds ratio (OR) of the effects of radiotherapy and irreversible NB on decreased bladder capacity and decreased compliance. Irreversible NB was defined as the need for clean intermittent catheterization at the last follow-up. Results: At the median follow-up period of 41 months, $60 \%$ of the patients continued to require clean intermittent catheterization. Of patients with irreversible NB and radiotherapy, $80 \%$ had decreased bladder capacity and decreased compliance at UDS-2. For decreased bladder capacity and decreased compliance, ORs of adjuvant radiotherapy at UDS-2 were $38.42(\mathrm{p}<0.001)$ and $7.46(\mathrm{p}=0.001)$, respectively, while ORs of irreversible NB were $1.64(\mathrm{p}=0.527)$ and $3.42(\mathrm{p}=0.062)$, respectively. Detrusor contraction could be demonstrated in only $15 \%$ and $45 \%$ at UDS- 1 and UDS-2, respectively. However, regardless of improvement in detrusor con-
\end{abstract}


tractility, urodynamic studies revealed a high urethral resistance. Conclusions: Careful neurourological follow-up after RH is mandatory for patients who undergo adjuvant radiotherapy and have irreversible NB with impaired urethral relaxation.

\section{Keywords}

Urinary Bladder, Neurogenic, Clean Intermittent Catheterization, Hysterectomy, Radiotherapy

\section{Introduction}

Infrasacral neurogenic bladder (NB) after abdominal radical hysterectomy (RH) for cervical cancer is a well-recognized condition [1]. However, the diagnostic modalities and time to examination are variable, and there are few reports about lower urinary tract (LUT) management for this condition [1] [2]. The reported incidences of LUT dysfunction are also variable; for example, the incidence of straining to void ranges from $40 \%$ to $100 \%$, reduced filling sensation from $30 \%$ to $60 \%$, and low compliance bladder (LC) from $20 \%$ to $50 \%$ [3]. More than $30 \%$ of patients suffer from long-lasting NB [3]. Cervical cancer usually affects middle-aged women and can be cured by modern multidisciplinary treatment, which achieves excellent five-year survival rates: $91.8 \%$ and $71.5 \%$ for Stage I and II disease, respectively [4]. Therefore, it is important that patients with NB after $\mathrm{RH}$ be evaluated by precise modalities and receive appropriate LUT management.

The pathophysiological mechanisms of NB after $\mathrm{RH}$ are multifactorial and not fully understood [5]. Postoperative NB occurs due to partial or complete disruption of the sympathetic and parasympathetic fibers running through the para-cervix and innervating the LUT [5]. In addition to peripheral nerve injuries, blood flow to the LUT is impaired, and the resulting tissue hypoxia may also have an impact on LUT function [6]. Bladder hypoxia will ultimately lead to low bladder compliance and progressively impair detrusor contractility [6]. Adjuvant radiotherapy can aggravate fibrotic change of the affected bladder and further compromise the bladder compliance and contractility [6]. The International Consultation on Incontinence-Research Society stated that urodynamic screening for the cause of LUT dysfunction is warranted before conservative management is initiated [6], and that if LUT dysfunction persists after the period of $6-12$ months of conservative management has been completed, a new urodynamic screening should be followed by appropriate treatment [6].

In Japan, $\mathrm{RH}$ has been performing according to the procedure developed by Okabayashi with modifications such as nerve-sparing RH [7] [8]. Okabayashi's $\mathrm{RH}$ is characterized by wide extirpation of parametrial tissue and separation of the posterior leaf of the vesicouterine ligament, enabling the surgeon to separate 
the bladder with the ureter completely from the lateral side of the cervix and vagina [8]. This means that Okabayashi's method may be classified as a Class IV radical hysterectomy in the classification of Piver's et al. [8]. Surgery plays a dominant role in treatment for cervical cancer due to concern that radiotherapy will cause permanent loss of ovarian function and sexual disturbances due to fibrosis of the vaginal canal [7] [9]. Consequently, in Japan, surgery is performed as the initial therapy for cervical cancer in $91 \%$ and $58 \%$ of patients with stage I and II disease, respectively [4] [7]. Nevertheless, of the patients undergoing RH, $19 \%$ of patients with Stage I disease and $49 \%$ of patients with Stage II disease received adjuvant radiotherapy or chemoradiation [4]. Moreover, the overall incidence of severe urological complications after radiotherapy for gynecological malignancies was comparatively higher in Japan than in the United States and Europe [10].

In the present study, to clarify which patients need careful neurourological management after RH, we retrospectively investigated data on LUT management and urodynamic studies (UDS) of patients referred to our NB clinic, with particular emphasis on the effects of adjuvant radiotherapy and reversibility of NB on the storage function as well as the effects of urethral resistance on the emptying function. Our hypotheses were:

1) Adjuvant radiotherapy highlighted LC predominantly in patients with irreversible NB, which reduced bladder capacity.

2) High urethral resistance involved the efficiency of bladder expression.

\section{Materials and Methods}

In 2005, based on the experience of spontaneous bladder perforation of three patients after RH with adjuvant radiotherapy as a late complication, the urologists, gynecologists, and nurses of Tsukuba University Hospital agreed that: 1) forceful bladder expression such as straining to void as LUT management for patients after RH was to be avoided [11]; 2) CIC was to be promptly introduced instead; and 3) after discharge all the patients who needed CIC at discharge were to be managed at the NB clinic of Tsukuba University Hospital. After approval of the clinical research ethics committee at Tsukuba University Hospital (approval number: H28-149) with the 1964 Helsinki declaration and its later amendments or complete ethical standards, the clinical charts of 69 consecutive patients who needed CIC at discharge and were referred to the NB clinic between 2005 and 2009 were reviewed in this study. During the same period, 118 patients underwent RH at our institution; therefore, the subjects comprised 58\% (69/118) of all RH patients, which means that the remaining 49 patients did not need CIC at discharge and were not referred to the NB clinic.

The LUT management plan of the NB clinic is shown in Figure 1. Bladder expression to facilitate emptying the bladder is not recommended because it increases bladder pressure, risk of vesicoureteral reflux, and pressure propagation to the kidneys and pelvic floor, potentially resulting in long-term renal and 


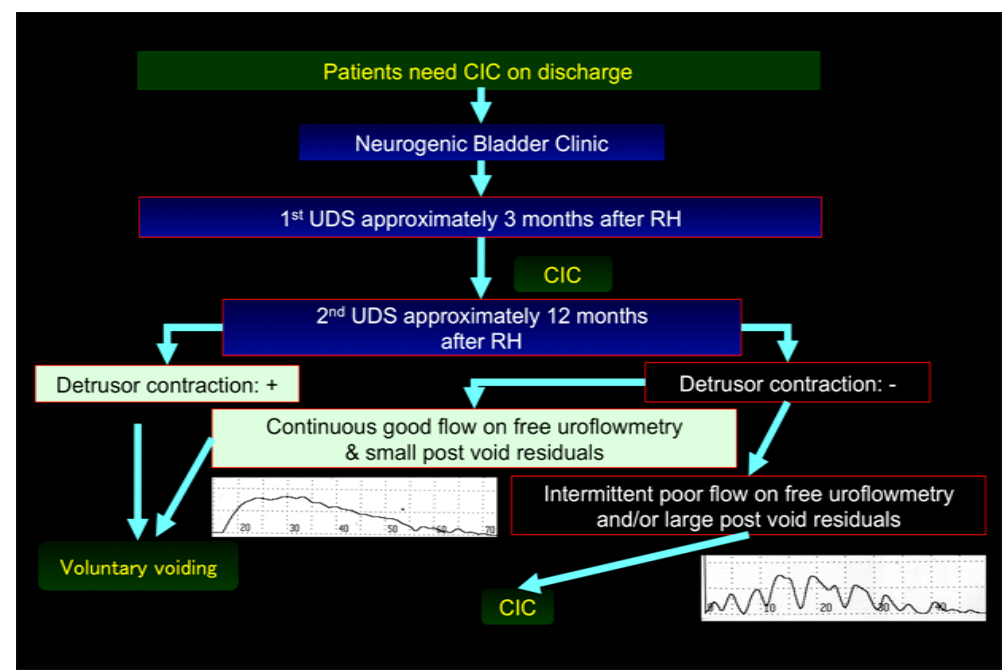

Figure 1. Lower urinary tract management plan for post-RH patients. RH: radical hysterectomy; CIC: clean intermittent catheterization; UDS: urodynamic study.

pelvic floor damage [11]. Therefore, CIC should be substituted for bladder expression [11]. Patients were thoroughly instructed about the pathophysiology of NB and the need for LUT management after the first UDS (UDS-1) performed within six months after completion of the treatment for cervical cancer. Because LUT function is usually recovered around 12 months after radical pelvic surgery [6], the second UDS (UDS-2) was performed at that time. If sufficient detrusor contraction was present or if sufficient detrusor contraction was not demonstrated but a continuous flow pattern was evident on repeat uroflowmetries, CIC was gradually stopped. On the other hand, if detrusor contraction was not demonstrated and an intermittent flow pattern with a poor flow rate was shown on repeated uroflowmetries, CIC was continued.

UDS was conducted according to recommendations of the International Continence Society [12]. A JANUS system (Amco Inc., Tokyo, Japan) was used for UDS. To avoid bladder over-distention, the infusion was stopped if urinary sensation did not appear or was significantly reduced when the infused volume exceeded $500 \mathrm{~mL}$ or detrusor pressure exceeded $40 \mathrm{~cm} \mathrm{H}_{2} \mathrm{O}$. Abnormal filling sensation was defined as the lack of at least one sensation of the first sensation of filling (FS), first desire to void (FDV), strong desire to void (SDV), and maximum cystometric capacity (MCC) [13], or FDV $>300 \mathrm{~mL}$ or MCC $>500 \mathrm{~mL}$, which are customarily used at our NB clinic. Bladder compliance $<20 \mathrm{~mL} / \mathrm{cm}$ $\mathrm{H}_{2} \mathrm{O}$ was defined as LC, while $<10 \mathrm{~mL} / \mathrm{cm} \mathrm{H}_{2} \mathrm{O}$ was defined as severe LC [2]. Because detrusor contraction in the emptying phase was approximately $10 \mathrm{~cm}$ $\mathrm{H}_{2} \mathrm{O}$ or less and high pressure abdominal straining compensated for detrusor underactivity in most cases, intravesical pressure (Pves) was used in this study. In addition, the interpretation of perianal surface electromyography findings due to abdominal straining is very difficult so urethral resistance $\left(\mathrm{R}, \mathrm{cmH}_{2} \mathrm{O}\right.$ / $\left.(\mathrm{mL} / \mathrm{s})^{2}\right)$, calculated by the equation Pves at maximum flow rate (Qmax) divided 
by $(\mathrm{Qmax})^{2}$ was used to evaluate urethral function during emptying [14]. $\mathrm{R}>$ $0.30 \mathrm{cmH}_{2} \mathrm{O} /(\mathrm{mL} / \mathrm{s})^{2}$ was defined as high $\mathrm{R}[15]$.

In the present study, patient characteristics, LUT management, and UDS-1 and UDS-2 findings were reviewed. MCC and bladder compliance were compared between RH alone and RH followed by adjuvant radiotherapy, and between reversible and irreversible NB, which was defined as the need for CIC at the last follow-up.

Statistical analysis was performed using JMP8 (SAS Institute Inc.). Data are shown as mean \pm SD unless otherwise indicated. Analysis of variance was used for unpaired data, paired t-test for paired data, and Pearson's chi-square test or Fisher's exact test for contingency tables. Logistic analysis was used for calculating the odds ratio (OR) of radiotherapy and irreversible NB for MCC $<300 \mathrm{~mL}$ and LC. Spearman's rank correlation coefficient was used for analyzing the correlation between $\mathrm{R}$ and the voiding parameters in UDS-2. $\mathrm{P}<0.05$ was considered to be statistically significant.

\section{Results}

\subsection{Patient Characteristics}

Sixty-nine patients were referred to the NB clinic, but seven patients were lost due to early recurrence or metastasis (4) or refusal of subsequent visits to the NB clinic (3). Therefore, clinical data of the remaining 62 patients were reviewed. At $\mathrm{RH}$, patients were $45.3 \pm 10.4$ years old. Co-morbidities and previous surgical histories included diabetes mellitus (3), mild lumbar spondylosis (2), hyperthyroidism (1), hypothyroidism (1), epilepsy (1), ovariectomy for ovarian cancer (1), mastectomy for breast cancer (1), and enucleation for meningioma (1). Pharmacotherapies had these medical diseases under control, and no recurrent malignant and benign neoplasms occurred during the study period. Forty-three patients had stage I disease (IA2: 1, IB1: 30, IB2: 12), and 19 had stage II disease (IIA: 3, IIB: 16). All patients underwent Okabayashi's radical hysterectomy. According to surgical records, a uni- or bilateral nerve-sparing procedure was attempted in 56 patients (90\%). Thirty-five (51\%) received adjuvant radiotherapy according to the Japan Society of Gynecologic Oncology guidelines, that is, using a 4 -field box technique, whole pelvic irradiation with a total dose of 50.4 Gy was administered over a 5-week period. The median follow-up period was 41.3 months (range 12.4 - 80.1 months). Patients characteristics according to reversibility of NB are shown in Table 1 .

\subsection{Lower Urinary Tract Management}

At last follow-up, 25 patients (40\%) voluntarily voided without the aid of catheterization, while $37(60 \%)$ continued CIC. Sixty per cent and $58 \%$ of patients with stage I and II diseases, respectively, continued CIC $(\mathrm{p}=1.000)$. The average period to voluntary voiding was 14.2 months (median: 14 months; range: 2 - 26 months), and six patients took more than 18 months to terminate CIC. 
Table 1. Patients characteristics according to reversibility of neurogenic bladder.

\begin{tabular}{cccc}
\hline & Reversible NB & Irreversible NB & $\mathrm{p}$ \\
\hline $\mathrm{n}$ & 25 & 37 & \\
Age & $44.6 \pm 9.4$ & $44.9 \pm 11.2$ & $0.915^{*}$ \\
$\begin{array}{c}\text { Follow-up period (months), } \\
\text { median (range) } \\
\text { Stage }\end{array}$ & $24(12-54)$ & $28(12-56)$ & $0.096^{*}$ \\
I/II/III & $17 / 8 / 0$ & & \\
Adjuvant radiotherapy, n (\%) & $13(52)$ & $26 / 10 / 1$ & $0.755^{* *}$ \\
\hline
\end{tabular}

Values are presented as mean \pm standard deviation. NB: neurogenic bladder. ${ }^{\star}$ Analysis of variance; ${ }^{*}$ Pearson's chi-square test.

\subsection{Urodynamic Findings on Storage Function}

UDS findings on the storage phase are shown in Table 2 and Table 3. Compared with UDS-1, the incidence of abnormal filling sensation in UDS-2 was not significantly decreased, while the incidence of MCC $<300 \mathrm{~mL}$ was significantly increased ( $\mathrm{p}=0.004$, Table 2 ). UDS-2 revealed detrusor overactivity (DO) in 10 patients (19.6\%), although the presence or absence of DO was not associated with a continuation of CIC (a $60 \%$ CIC rate in patients with DO vs. a $62 \%$ CIC rate in patients without DO). Bladder compliance was not improved and the incidence of LC or severe LC was not decreased in UDS-2 (Table 2). According to the reversibility of NB, UDS findings in the storage phase did not show any statistical difference (Table 3). In terms of lower urinary tract symptoms (LUTS), one and four patients at UDS-1, and five and two patients at UDS- 2 complained of stress urinary incontinence and nighttime urinary leakage. The average bladder compliance of these incontinent patients was $12.9 \pm 6.3 \mathrm{~mL} / \mathrm{cm} \mathrm{H}_{2} \mathrm{O}$ and 9.3 $\pm 5.8 \mathrm{~mL} / \mathrm{cm} \mathrm{H}_{2} \mathrm{O}$ at UDS-1 and UDS-2, respectively. Of 10 patients with severe LC at UDS-2, eight patients took anticholinergic drugs, including propiverine 40 $\mathrm{mg}$ /day by six patients and tolterodine $4 \mathrm{mg}$ /day by two; however, follow-up urodynamic studies showed no remarkable improvement in the storage function (data not shown).

\subsection{Effects of Adjuvant Radiotherapy and Reversibility of NB on the Storage Function}

In terms of the effects of adjuvant radiotherapy on storage function, the patients with radiotherapy had significantly smaller MCC and lower bladder compliance than patients without radiotherapy, and had a significantly higher incidence of MCC $<300 \mathrm{~mL}$, LC, and severe LC than patients without radiotherapy (Table 4). On UDS-1 and UDS-2, ORs of MCC $<300 \mathrm{~mL}$ after radiotherapy were 11.86 (95\% CI, $2.01-227.10, \mathrm{p}=0.004)$ and $35.71(95 \% \mathrm{CI}, 8.00-261.93, \mathrm{p}<0.001)$, respectively, while ORs for LC after radiotherapy were 4.85 (95\% CI, $1.62-16.23$, p $=0.004)$ and $5.95(95 \% \mathrm{CI}, 1.88-21.07, \mathrm{p}=0.002)$, and for severe LC were 6.96 (95\% CI, $1.09-136.11, \mathrm{p}=0.039)$ and 6.25 (95\% CI, $1.40-44.33, \mathrm{p}=0.015)$, respectively. The incidences of MCC $<300 \mathrm{~mL}$ and LC in reversible and 
Table 2. Urodynamic parameters after radical hysterectomy.

\begin{tabular}{|c|c|c|c|}
\hline & $1^{\text {st }}$ UDS & $2^{\text {nd }}$ UDS & $\mathrm{p}$ \\
\hline \multicolumn{4}{|c|}{ Storage function after radical hysterectomy } \\
\hline $\mathrm{n}$ & 61 & 54 & \\
\hline Time (month), median (range) & $3(1-6)$ & $12(8-17)$ & \\
\hline \multicolumn{4}{|l|}{ Filling sensation $(\mathrm{mL})$} \\
\hline FS & $209.3 \pm 107.9$ & $180.1 \pm 104.7$ & $0.151^{\star}$ \\
\hline FDV & $265.3 \pm 97.2$ & $234.1 \pm 98.7$ & $0.017^{\star}$ \\
\hline SDV & $324.6 \pm 92.7$ & $277.1 \pm 98.1$ & $<0.001^{*}$ \\
\hline MCC & $388.3 \pm 96.6$ & $328.8 \pm 114.3$ & $<0.001^{\star}$ \\
\hline Abnormal filling sensation\# (\%) & 56 & 39 & $0.071^{\star *}$ \\
\hline $\mathrm{MCC}<300 \mathrm{~mL}(\%)$ & 16 & 41 & $0.004^{* *}$ \\
\hline Compliance $\left(\mathrm{mL} / \mathrm{cmH}_{2} \mathrm{O}\right)$ & $32.8 \pm 37.2$ & $26.9 \pm 18.7$ & $0.382^{*}$ \\
\hline$<20(\%)$ & 38 & 43 & $0.593^{* *}$ \\
\hline$<10(\%)$ & 11 & 20 & $0.190^{* *}$ \\
\hline \multicolumn{4}{|c|}{ Emptying function after radical hysterectomy } \\
\hline $\mathrm{n}$ & 59 & 50 & \\
\hline Voiding on UDS n, (\%) & $13(22)$ & $25(50)$ & $0.003^{* *}$ \\
\hline Contractile detrusor, $\mathrm{n}(\%)$ & $2(15)$ & $12(48)$ & $0.077^{* * *}$ \\
\hline \multicolumn{4}{|l|}{ Pressure and flow parameters } \\
\hline PvesQmax $\left(\mathrm{cm} \mathrm{H}_{2} \mathrm{O}\right)$ & $81.0 \pm 37.1$ & $68.0 \pm 29.8$ & $0.514^{*}$ \\
\hline $\mathrm{Qmax}(\mathrm{mL} / \mathrm{sec})$ & $9.2 \pm 5.3$ & $8.6 \pm 5.0$ & $0.642^{*}$ \\
\hline Qave (mL/sec) & $3.4 \pm 1.9$ & $3.0 \pm 1.9$ & $0.340^{*}$ \\
\hline $\mathrm{VV}(\mathrm{mL})$ & $166.2 \pm 140.7$ & $177.8 \pm 136.7$ & $0.652^{*}$ \\
\hline $\operatorname{PVR}(\mathrm{mL})$ & $214.5 \pm 149.3$ & $226.0 \pm 129.8$ & $0.904^{*}$ \\
\hline $\mathrm{VT}(\mathrm{sec})$ & $65.6 \pm 39.4$ & $90.8 \pm 64.4$ & $0.177^{*}$ \\
\hline $\mathrm{R}^{+}\left(\mathrm{cmH}_{2} \mathrm{O} /(\mathrm{mL} / \mathrm{sec})^{2}\right)$ & $\begin{aligned} & 2.17 \pm 2.47 \\
& \text { (median: } 0.85, \text { IQR: } 0.46,3.68 \text { ) }\end{aligned}$ & $\begin{array}{c}4.57 \pm 15.55 \\
\text { (median: } 1.19, \text { IQR: } 0.45,2.32 \text { ) }\end{array}$ & $0.417^{*}$ \\
\hline
\end{tabular}

Values are presented as mean \pm standard deviation. UDS: urodynamic study; FS: first sensation of filling; FDV: first desire to void; SDV, strong desire to void; MCC: maximum cystometric capacity; PvesQmax: intravesical pressure at maximum flow rate; Qmax: maximum flow rate; Qave: average flow rate; VV: voided volume; PVR: post-void residual volume; VT: voiding time; R: urethral resistance. ${ }^{*}$ Paired $\mathrm{t}$-test; ${ }^{* *}$ Pearson's chi-square test; ${ }^{* * *}$ Fisher's exact test; \#Lack of at least one filling sensation or FDV $>300 \mathrm{~mL}$ or $\mathrm{MCC}>500 \mathrm{~mL} ;+=\operatorname{PvesQmax} /(\mathrm{Qmax})^{2}$.

irreversible NB are shown in Figure 2. For MCC $<300 \mathrm{~mL}$ and LC, ORs of radiotherapy were $38.42(95 \% \mathrm{CI}, 8.36-293.31, \mathrm{p}<0.001)$ and 7.46 (95\% CI, $2.19-20.13$, $\mathrm{p}=0.001$ ), respectively, while ORs of irreversible NB were 1.64 (95\% CI, $0.35-8.26$, $\mathrm{p}=0.527)$ and $3.42(95 \% \mathrm{CI}, 0.94-14.49, \mathrm{p}=0.062)$, respectively.

\subsection{Urodynamic Findings on Emptying Function}

In the emptying phase, only $22 \%$ and $50 \%$ of patients were able to void during 


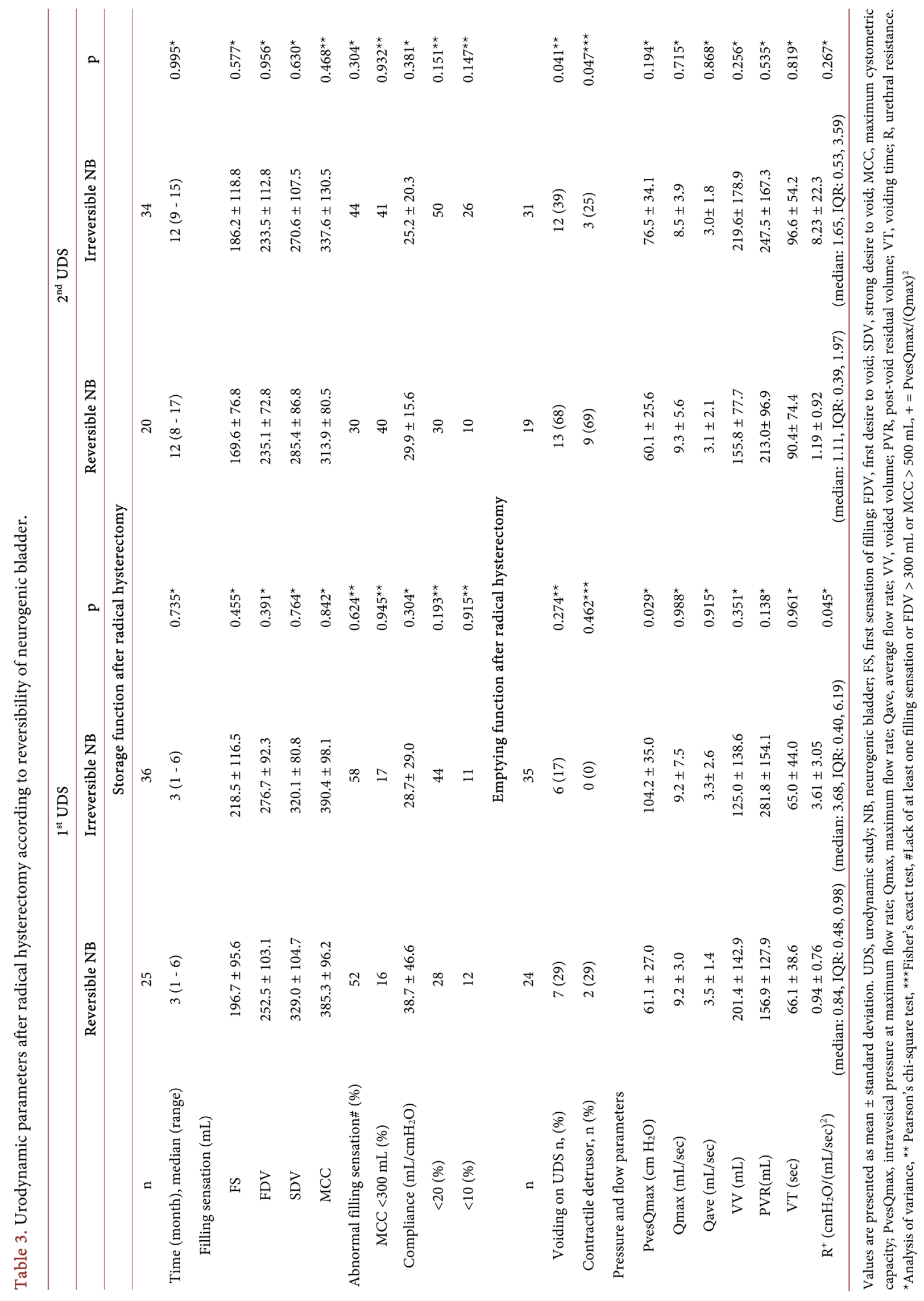


Table 4. Maximum cystometric capacity and bladder compliance in patients with or without adjuvant radiotherapy.

\begin{tabular}{|c|c|c|c|c|c|c|}
\hline & \multicolumn{3}{|c|}{$1^{\text {st }}$ UDS } & \multicolumn{3}{|c|}{$2^{\text {nd }}$ UDS } \\
\hline & $\begin{array}{c}\mathrm{RT} \\
(\mathrm{n}=31)\end{array}$ & $\begin{array}{c}\text { no RT } \\
(\mathrm{n}=30)\end{array}$ & $\mathrm{p}$ & $\begin{array}{c}\mathrm{RT} \\
(\mathrm{n}=27)\end{array}$ & $\begin{array}{c}\text { no RT } \\
(\mathrm{n}=27)\end{array}$ & $\mathrm{p}$ \\
\hline $\operatorname{MCC}(\mathrm{mL})$ & $351.2 \pm 102.7$ & $426.6 \pm 73.5$ & $0.002^{*} 2$ & $265.9 \pm 93.0$ & $391.7 \pm 98.8$ & $<0.001^{\star}$ \\
\hline $\mathrm{MCC}<300, \mathrm{n}(\%)$ & $9(29.0)$ & $1(3.3)$ & $0.013^{* *}$ & $20(74.1)$ & $2(7.4)$ & $<0.001^{\star *}$ \\
\hline Compliance $\left(\mathrm{mL} / \mathrm{cm} \mathrm{H}_{2} \mathrm{O}\right)$ & $23.6 \pm 19.7$ & $42.3 \pm 47.8$ & $0.049^{\star}$ & $19.9 \pm 15.3$ & $33.9 \pm 19.4$ & $0.005^{\star}$ \\
\hline Compliance $<20, \mathrm{n}(\%)$ & $17(54.8)$ & $6(20.0)$ & $0.005^{\star * *}$ & $17(63.0)$ & $6(22.2)$ & $0.003^{* * *}$ \\
\hline Compliance < 10, n (\%) & $6(19.4)$ & $1(3.3)$ & $0.104^{* *}$ & $9(33.3)$ & $2(7.4)$ & $0.039^{* *}$ \\
\hline
\end{tabular}

Values are presented as mean \pm standard deviation. UDS: urodynamic study; MCC: maximum cystometric capacity; RT: radiotherapy. ${ }^{*}$ Unpaired t-test; ${ }^{* *}$ Fisher's exact test; ${ }^{* * *}$ Pearson's chi-square test.

UDS-1 and UDS-2, respectively (Table 2). Of these patients, detrusor contraction could be demonstrated in only $15 \%$ and $45 \%$ at UDS- 1 and UDS-2, respectively, which indicated a trend toward improved detrusor contractile function (Table 2). However, $\mathrm{R}$ did not show significant difference between UDS-1 (median: $\left.0.85 \mathrm{cmH}_{2} \mathrm{O} /(\mathrm{mL} / \mathrm{s})^{2}\right)$ and UDS-2 (median: $\left.1.19 \mathrm{cmH}_{2} \mathrm{O} /(\mathrm{mL} / \mathrm{s})^{2}\right)$. In addition, regardless of improvement in detrusor contractility, UDS revealed an obstructive voiding pattern, that is, high Pves (contractile patients: $59.1 \pm 30.49 \mathrm{~cm}$ $\mathrm{H}_{2} \mathrm{O}$, and acontractile patients: $76.3 \pm 27.7 \mathrm{~cm} \mathrm{H}_{2} \mathrm{O}, \mathrm{p}=0.152$ ) during voiding and low Qmax (contractile patients: $9.2 \pm 5.8 \mathrm{~mL} / \mathrm{sec}$ and acontractile patients: $8.1 \pm 4.2 \mathrm{~mL} / \mathrm{sec}, \mathrm{p}=0.591)$, which implied hydraulic energy loss during voiding that was represented by a high $\mathrm{R}$ (contractile patients: median; $1.10 \mathrm{cmH}_{2} \mathrm{O}$ / $(\mathrm{mL} / \mathrm{s})^{2}$ and acontractile patients: median; $\left.1.28 \mathrm{cmH}_{2} \mathrm{O} /(\mathrm{mL} / \mathrm{s})^{2}, \mathrm{p}=0.335\right)$. At UDS-2, 21 of 25 patients (84\%) showed high R. As shown in Table 5, R strongly and negatively correlated with Qmax, average flow rate, and voided volume, but moderately and positively correlated with post-void residual urine volume. According to the reversibility of NB, UDS findings in the emptying phase did not show any statistical difference in most of the parameters, except Pves at Qmax and R at UDS-1 (Table 3). Voiding LUTS could not be evaluated because almost all patients performed CIC at UDS-1 and UDS-2.

\section{Discussion}

RH sometimes causes infrasacral NB, which often requires CIC transiently or permanently. In the present study, 37 (60\%) of the patients who were referred to the NB clinic continued CIC at the median follow-up of 41.3 months, which was defined as irreversible NB. These patients are probably more prone to develop urological complications secondary to severe infrasacral NB due to extensive peripheral nerve damage; however, as shown in Table 3, most of the UDS parameters did not reveal statistically or clinically significant differences between reversible NB and irreversible NB. Consequently, it seems that UDS findings as a 
Table 5. Correlation between urethral resistance and voiding parameters.

\begin{tabular}{ccc}
\hline & Spearman's rank correlation coefficient $(\rho)$ & $\mathrm{p}$ \\
\hline Intravesical pressure at & -0.0231 & 0.9148 \\
maximum flow rate & -0.9133 & $<0.0001$ \\
Maximum flow rate & -0.8631 & $<0.0001$ \\
Average flow rate & -0.7017 & 0.0001 \\
Voided volume & 0.535 & 0.0071 \\
Post-void residual volume & 0.1374 & 0.522 \\
\hline Voiding time &
\end{tabular}

Spearman's rank correlation coefficient was used for analyzing the correlation between urethral resistance and the voiding parameters in UDS-2.

whole did not adequately identify patients who need careful neurourological management. Because it was reported that the overall incidence of severe urological complications after radiotherapy for gynecological malignancies was comparatively higher in Japan than in the United States and Europe [10], it is conceivable that we should take into consideration not only the reversibility of $\mathrm{NB}$ after RH, but also the effects of adjuvant radiotherapy.

Although much attention is paid to emptying dysfunction caused by detrusor underactivity or acontractile detrusor after $\mathrm{RH}$, the present study showed that significant storage dysfunctions were present despite prompt initiation of CIC, especially in patients undergoing adjuvant radiotherapy. High pressure storage dysfunction represented by LC has significant adverse effects on the upper and lower urinary tract [16]. In the present study, LC occurred six times more frequently in the patients with adjuvant radiotherapy than those without radiotherapy. There have been several reports of an association between storage dysfunction and radiotherapy. At six months after $\mathrm{RH}$, bladder compliance in the $\mathrm{RH}$ alone group had increased four times or more compared with that on postoperative day $10\left(22.3\right.$ to $\left.87.6 \mathrm{~mL} / \mathrm{cm} \mathrm{H}_{2} \mathrm{O}\right)$, but it increased only 2.5 times in the $\mathrm{RH}$ with adjuvant radiotherapy group (13.3 to $38.1 \mathrm{~mL} / \mathrm{cm} \mathrm{H}_{2} \mathrm{O}$ ) [17]. At about seven years, LC was revealed by UDS in $24 \%$ and $60 \%$ of the $\mathrm{RH}$ alone and $\mathrm{RH}$ with radiotherapy groups, respectively [18]. Chuang et al. pointed out that the mean interval between RH and the first visit for urological management of NB was significantly shorter in the $\mathrm{RH}$ with radiotherapy group (5.9 years) than the $\mathrm{RH}$ alone group (11.3 years) [2]. Moreover, the present study showed that radiotherapy highlighted LC, predominantly in patients with irreversible NB (Figure 2), and for LC, the estimated OR of radiotherapy together with irreversible NB was 25.51 $(7.46 \times 3.42)$. This result is in line with a previous report by Oda et al. who showed that risk factors for LC were non-nerve sparing RH (OR: 3.4), adjuvant radiotherapy (OR: 10.3), and bladder expression (OR: 2.9) [19]. The morphological andpathophysiological effects of radiotherapy on the bladder complicated by infrasacral NB have not been studied yet. Also, it has not been fully elucidated whether surgical injury to the peripheral nerve aggravates irradiation-induced 


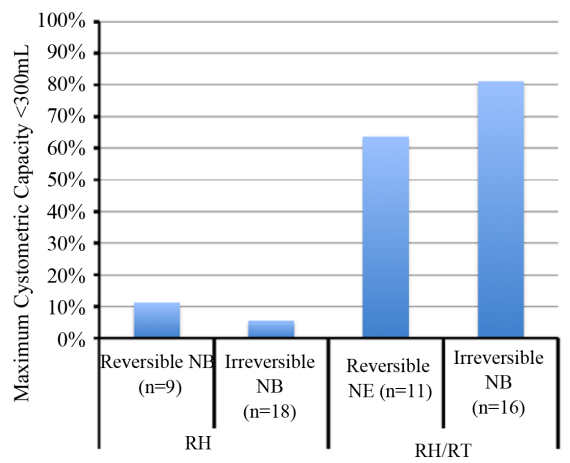

(a)

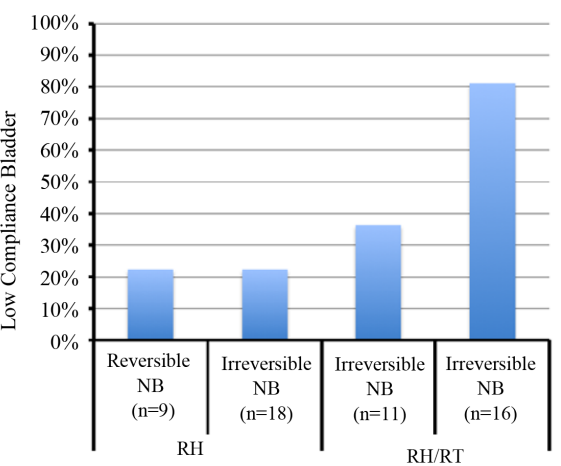

(b)

Figure 2. Impact of radiotherapy and reversibility of neurogenic bladder on maximum cystometric capacity and bladder compliance. Rates of patients with maximum cystometric capacity less than $300 \mathrm{~mL}$ (a) and with are demonstrated (b). There are significant differences among these groups. A: $\mathrm{p}<0.001$, Pearson's chi-square test; $\mathrm{B}: \mathrm{p}=0.002$, Pearson's chi-square test. NB: neurogenic bladder; RH: radical hysterectomy; RT: radiotherapy.

peripheral neuropathy. Taken together, gynecologic oncologists and neurourologists are advised to pay attention to LC, especially in patients who received adjuvant radiotherapy with irreversible $\mathrm{NB}$, and to carefully monitor the upper and lower urinary tract of these patients [2] [17]. Moreover, in order to elucidate the presence or absence of LC, we think that UDS should be proactively performed in patients with any doubt about nerve preservation and adjuvant radiotherapy.

In the present study, UDS revealed high urethral resistance without temporal improvement, regardless of the detrusor contractile status on UDS-2. This means that more hydraulic energy produced by an increase in intravesical pressure is lost through the urethra, which is assumed to be a rigid tube, in patients undergoing RH than in normal subjects [15]. In the present study, R negatively correlated with urinary flow rate and voided volume, but positively correlated with post-void residual urine volume. That was why the efficiency of bladder expression is too low for the patients to stop CIC. Impaired urethral relaxation would be a major cause of high R after RH. In infrasacral NB, the postganglionic adrenergic system, which is free from regulation by the parasympathetic post-ganglionic neurons due to parasympathetic denervation, is responsible for the urethral denervation supersensitivity to noradrenalin [20]. Damage to the inferior hypogastric plexus may also result in increased resistance at the bladder neck, although the precise mechanisms are not clear [3]. Taken together, impaired urethral relaxation, as well as impaired detrusor contractility, profoundly involves emptying dysfunction after RH. Therefore, as recommended by the International Consultation on Incontinence [11], the efficiency of bladder expression should be urodynamically evaluated before this method is selected for LUT management, even in the patients in whom nerve-sparing was attempted. In addition, $\mathrm{R}$ might be used for evaluating the efficiency of bladder expression.

There are several limitations to the present study. This study was a retrospec- 
tive study and conducted with the patients who needed CIC at discharge. Consequently, this study lacked a control group. In addition, the time required to perform UDS-1 and UDS-2 was not uniform, preoperative UDS was not performed, and a valid questionnaire for LUT symptoms was not used. However, reports on long-term LUT management based on UDS findings after RH and thorough investigation by serial UDS are sparse [2] [3]. It is conceivable that UDS could be used to detect potentially dangerous situations in high-risk patients who undergo adjuvant radiotherapy and have irreversible NB with high $\mathrm{R}$, allowing better urologic care to modify long-term LUTD and renal deterioration.

\section{Conclusion}

In conclusion, adjuvant radiotherapy highlighted LC in patients with irreversible NB that was defined as the need for CIC at the last follow-up. The impaired urethral relaxation, as well as impaired detrusor contractility, profoundly affects the emptying dysfunction after RH. Therefore, careful long-term neurourological follow-up is mandatory for patients with irreversible NB after adjuvant radiotherapy and for patients who have impaired urethral relaxation because long-term survival can be expected after RH. Moreover, inefficient bladder expression should be avoided to prevent the progression of storage dysfunction, and CIC is recommended to accomplish low pressure, residual-free voiding, especially in patients who received adjuvant radiotherapy with irreversible NB.

\section{References}

[1] Plotti, F., Angioli, R., Zullo, M.A., Sansone, M., Altavilla, T., Antonelli, E., et al. (2011) Update on Urodynamic Bladder Dysfunctions after Radical Hysterectomy for Cervical Cancer. Critical Reviews in Oncology/Hematology, 80, 323-329. https://doi.org/10.1016/j.critrevonc.2010.12.004

[2] Chuang, F.C. and Kuo, H.C. (2009) Management of Lower Urinary Tract Dysfunction after Radical Hysterectomy with or without Radiotherapy for Uterine Cervical Cancer. Journal of the Formosan Medical Association, 108, 619-626. https://doi.org/10.1016/S0929-6646(09)60382-X

[3] Jackson, K.S. and Naik, R. (2006) Pelvic Floor Dysfunction and Radical Hysterectomy. International Journal of Gynecological Cancer, 16, 354-363. https://doi.org/10.1111/j.1525-1438.2006.00347.x

[4] Yamagami, W. and Aoki, D. (2015) Annual Report of the Committee on Gynecologic Oncology, the Japan Society of Obstetrics and Gynecology. Journal of Obstetrics and Gynaecology Research, 41, 1861-1869. https://doi.org/10.1111/jog.12833

[5] Laterza, R.M., Sievert, K.D., de Ridder, D., Vierhout, M.E., Haab, F., Cardozo, L., et al. (2015) Bladder Function after Radical Hysterectomy for Cervical Cancer. Neurourology and Urodynamics, 34, 309-315. https://doi.org/10.1002/nau.22570

[6] Bosch, J.L., Norton, P. and Jones, J.S. (2012) Should We Screen for and Treat Lower Urinary Tract Dysfunction after Major Pelvic Surgery?: ICI-RS 2011. Neurourology and Urodynamics, 31, 327-329. https://doi.org/10.1002/nau.22218

[7] Todo, Y., Kuwabara, M., Watari, H., Ebina, Y., Takeda, M., Kudo, M., et al. (2006) 
Urodynamic Study on Postsurgical Bladder Function in Cervical Cancer Treated with Systematic Nerve-Sparing Radical Hysterectomy. International Journal of Gynecological Cancer, 16, 369-375. https://doi.org/10.1111/j.1525-1438.2006.00345.x

[8] Fujii, S., Takakura, K., Matsumura, N., Higuchi, T., Yura, S., Mandai, M., et al. (2007) Anatomic Identification and Functional Outcomes of the Nerve Sparing Okabayashi Radical Hysterectomy. Gynecologic Oncology, 107, 4-13.

https://doi.org/10.1016/j.ygyno.2007.08.076

[9] Ebina, Y., Yaegashi, N., Katabuchi, H., Nagase, S., Udagawa, Y., Hachisuga, T., et al. (2015) Japan Society of Gynecologic Oncology Guidelines 2011 for the Treatment of Uterine Cervical Cancer. International Journal of Clinical Oncology, 20, 240-248. https://doi.org/10.1007/s10147-015-0806-7

[10] Fujikawa, K., Miyamoto, T., Ihara, Y., Matsui, Y. and Takeuchi, H. (2001) High Incidence of Severe Urologic Complications Following Radiotherapy for Cervical Cancer in Japanese Women. Gynecologic Oncology, 80, 21-23. https://doi.org/10.1006/gyno.2000.6030

[11] Wyndaele, J.J., Castro, D., Madersbacher, H., Chartier-Kastler, E., Igawa, Y., Kovindha, A., et al. (2005) Neurogenic Urinary and Faecal Incontinence. In: Abrams, P., Cardozo, L., Khoury, S., Wein, A., Eds., Incontinence, Edition 2005, Health Publication Ltd., Paris, 1059-1162.

[12] Schäfer, W., Abrams, P., Liao, L., Mattiasson, A., Pesce, F., Spangberg, A., et al, (2002) Good Urodynamic Practices: Uroflowmetry, Filling Cystometry, and Pressure-Flow Studies. Neurourology and Urodynamics, 21, 261-274.

https://doi.org/10.1002/nau.10066

[13] Wyndaele, J.J. and De Wachter, S. (2008) The Sensory Bladder (1): An Update on the Different Sensations Described in the Lower Urinary Tract and the Physiological Mechanisms behind Them. Neurourology and Urodynamics, 27, 274-278. https://doi.org/10.1002/nau.20510

[14] Yamanishi, T., Yasuda, K., Tojo, M., Hattori, T., Sakakibara, R. and Shimazaki, J. (1994) Improvement of Urethral Resistance after the Administration of an Alpha-Adrenoceptor Blocking Agent, Urapidil, for Neuropathic Voiding Dysfunction. Paraplegia, 32, 271-276. https://doi.org/10.1038/sc.1994.47

[15] Smith, J.C. (1968) Urethral Resistance to Micturition. British Journal of Urology, 40, 125-156. https://doi.org/10.1111/j.1464-410X.1968.tb09868.x

[16] McGuire, E.J., Woodside, J.R., Borden, T.A. and Weiss, R.M. (1981) Prognostic Value of Urodynamic Testing in Myelodysplastic Patients. Journal of Urology, 126, 205-209. https://doi.org/10.1016/S0022-5347(17)54449-3

[17] Oh, J.K., Choo, M.S., Lee, J., Park, N.H. and Oh, S.J. (2012) Short-Term Effect of Radical Hysterectomy with or without Adjuvant Radiation Therapy on Urodynamic Parameters in Patients with Uterine Cervical Cancer. International Neurourology Journal, 16, 91-95. https://doi.org/10.5213/inj.2012.16.2.91

[18] Lin, H.H., Sheu, B.C., Lo, M.C. and Huang, S.C. (1998) Abnormal Urodynamic Findings after Radical Hysterectomy or Pelvic Irradiation for Cervical Cancer. International Journal of Gynecology \& Obstetrics, 63, 169-174. https://doi.org/10.1016/S0020-7292(98)00158-1

[19] Oda, Y., Todo, Y., Hanley, S., Hosaka, M., Takeda, M., Watari, H., et al. (2011) Risk Factors for Persistent Low Bladder Compliance after Radical Hysterectomy. International Journal of Gynecological Cancer, 21, 167-272. https://doi.org/10.1097/IGC.0b013e318204c3df 
[20] Koyanagi, T., Morita, H., Taniguchi, K., Kubota, M., Shinno, Y. and Takamatsu, T. (1998) Neurogenic Urethra: Clinical Relevance of Isolated Neuropathic Dysfunction of the Urethra, and the Denervation Supersensitivity of the Urethra Revisited. European Urology, 15, 77-83. https://doi.org/10.1159/000473401 